\title{
The first illustrated book on gymnastics
}

\section{De arte gymnastica, Girolamo Mercuriale (I530-1606) Amsterdam, 1672}

Girolamo Mercuriale, who was professor of medicine at Bologna and Pisa, had many medical interests and was a prolific writer. The Sibbald Library contains 13 of his books including his best known work, De arte gymnastica, which was first published in 1569.

In De arte gymnastica, Mercuriale details how specific exercises affected specific diseases. He was one of the first therapists to suggest that exercise can be helpful or harmful depending on its use, duration, and intensity. On the basis of research, he recommends or prohibits certain physical activities, suggests proper equipment, and outlines training schedules and techniques. The influential illustrations which accompanied the work (from the second [1573] edition onwards) were 16th century imaginative reconstructions of athletics in the Classical world.

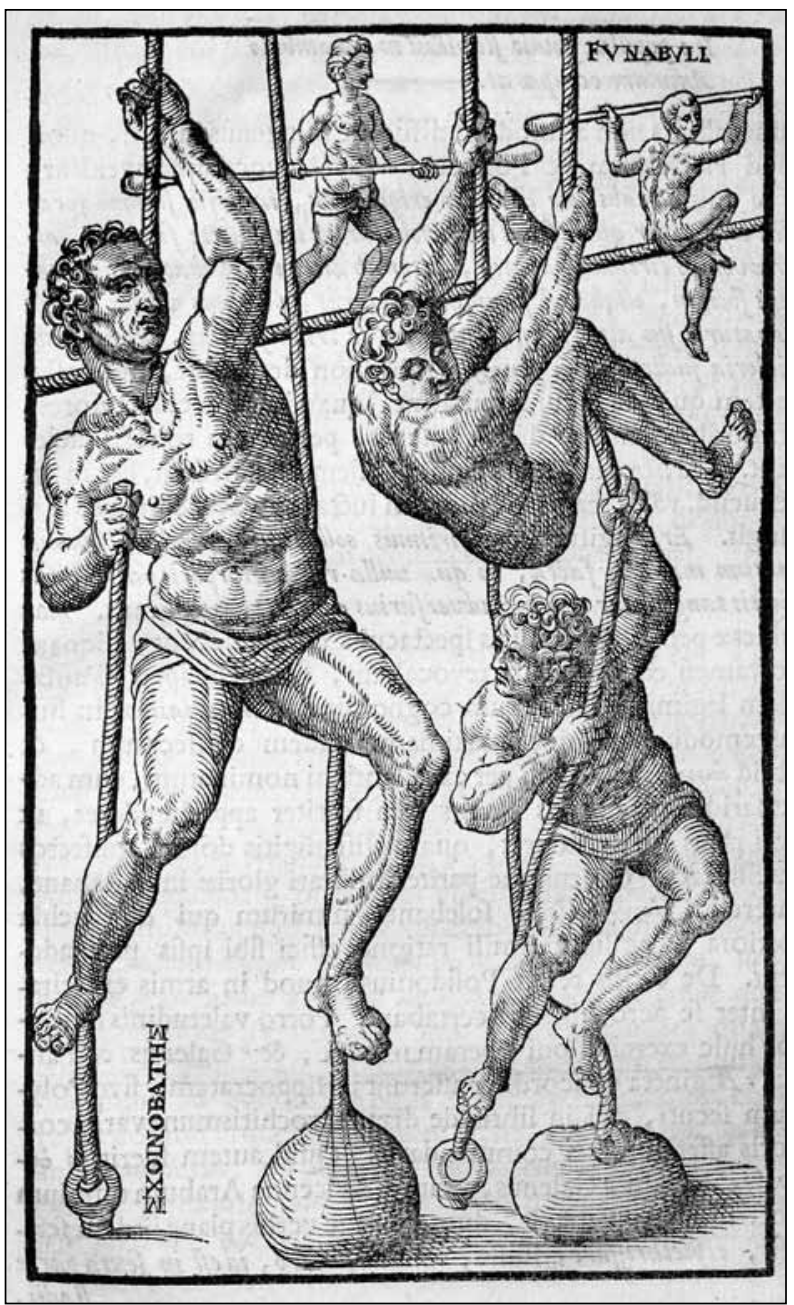

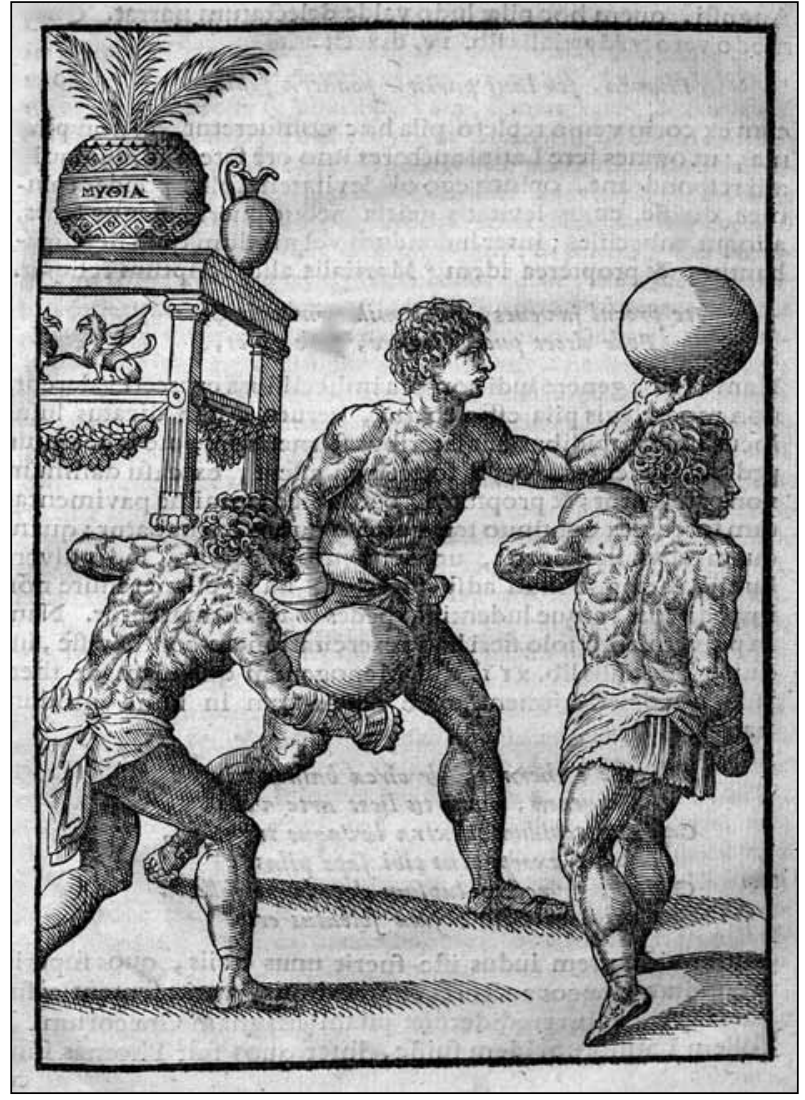

Mercuriale's reputation suffered during an outbreak of plague in Venice in the 1570s. He argued against quarantining and travelled freely while administrating treatment. When plague numbers started to rise, the Venetian Senate ordered Mercuriale to be quarantined himself. It was believed that Mercuriale's methods contributed to the spread of the plague which caused many deaths.

Over time, Mercuriale's reputation recovered and he remained in Padua until 1587, when he began teaching at the University of Bologna. His final career move was in 1593 when he was lured to Pisa by a huge salary of 1,800 gold crowns offered by the Grand Duke of Tuscany.

I Milne Sibbald Librarian 